\title{
INDIGENOUS, LOCAL AND REGIONAL TRADITIONS: VIEWS FROM RITUAL AND CEREMONY - AN AFTERWORD
}

\author{
Peter Wong Yih Jiun
}

Published online: 15 July 2020

To cite this article: Wong, P. Y. J. 2020. Indigenous, local and regional traditions: Views from ritual and ceremony - An afterword. International Journal of Asia Pacific Studies 16 (2): 117-121. https://doi.org/10.21315/ijaps2020.16.2.6

To link to this article: https://doi.org/10.21315/ijaps2020.16.2.6

These four papers across different disciplines and different cultures, while diverse, focus on the subject of ritual and ceremony. More specifically, these papers offer readers a chance to consider the world of each author from the vantages of ritual, considered either from a particular aspect or in general terms. Through these first steps taken here we glimpse some encouraging signs but also notice the difficulty of the task. Lessons have been learned, and they also have given rise to a number of questions.

First, if philosophy is expressed through providing general accounts, then we note the difficulty of making generalisations about a culture through consideration of particular rituals, such as the marriage ritual of the Ata Baolangu (Lembata, Eastern Indonesia) and the final mortuary ceremony of the Rak Mak Mak Marranungu (Northern Territory, Australia). While it's possible to make general observations of the rituals, such as Justin Wejak's point about the centrality of marriage for the Ata Baolangu, it is nevertheless confined to the view of a single community. One obvious way to proceed would be to consider a larger sample of rituals in the culture in order to build a more generalised picture of the meaning of marriage for the Ata Baolangu and beyond. Yet, this is still a standard academic approach to generating understanding, and well explored. While valuable, it is not precisely the aim of this exercise. But might there not be another way to generalise (if that approach is desired) from within the culture? From an outsider's point of view - and this is merely a suggestion - perhaps the Ata Baolangu could consider using some of their rituals as a general model for constructing their philosophical position. For example, they could adopt their ritual of marriage, 
with its emphasis on negotiation between invested parties as a basic approach, such that their philosophy is first and foremost a social act: the Ata Baolangu can engage in a dialogue with Christianity in developing a philosophy that incorporates both Catholic teachings and traditional Adat.

But perhaps the discursive approach is not the only way for articulating an indigenous or local philosophy. Another way of using ritual as a philosophical resource could be seen in Linda Ford's paper, in which a philosophy derived from Mirrwana and Wurrkama preparations for ceremony is proceduralised and expressed by way of diagrams or graphs. This is perfectly congruent with the tradition of pictorial expressions among the first people of Australia. The provision of an interpretative account or even justificatory one, if needed, then plays a secondary role. Such a practice is not without precedence in other cultures; one thinks of the use of diagrams in Western medieval and Islamic philosophies, in which diagrams play significant roles. There's also the Book of Changes in the Chinese classics that uses a system of symbols (the hexagrams) as the main expression of a philosophy of change, about which supplementary commentaries were written. However, the difference between a philosophy derived from ritual and those of the latter kind lies in its not being textually based. The touchstone of philosophy derived from ritual remains in the ritual performances - while the articulations themselves, be they graphical or discursive, are open to continual development and critique.

We also learn from reading Vo Van Sen and Nguyen Ngoc Tho's paper that flexibility and adaptability is needed when engaging with the world religious traditions; that in such engagements, vagueness and ambiguity are assets. As such, classical Western approaches in philosophy that seek to disambiguate through inquiring and analysing the meaning of a term might not be always helpful. Instead of seeking precision and clarity in the attempt to articulate a set of beliefs to which all must give their assent, the privileging of practice through the creation of common rituals might provide room for greater tolerance.

The obvious problem with this strategy is, when the project involves incorporating a tradition from the outside, by what measure is one to know whether one has compromised too much? And in a situation where there are diverse cultures, how are the needs of different cultures and their respective practices reconciled? Moreover, such attempts will always be in some measure political. How could we come to terms with compromising cherished traditional values for the sake of accommodating political realities? For example, how does one balance a community's particular values versus the desire to build a unified state? In other words, how does a community's 
efforts at maintaining its own identity deal with the pressures of nationalism, or perhaps, secularism? When is flexibility merely code for subjecting the philosophy or values of a community to serve the interests of politics? Surely, at some point, clarity and precision become important factors again in deciding these issues.

We need to be more discerning of what the so called "flexibility" involves. Ritual may provide its participants the flexibility of not requiring precision with regard to their beliefs. Yet, at the same time, ritual has its own inflexibility: in the performance of a ritual, one must do it in a particular way. ${ }^{1}$ Disagreements in ritual might be as intractable as conflicts about beliefs. Thus, with regard to adapting ritual to suit novel circumstances, how this occurs might be difficult and complex, which might even involve intellectual and ideological disputes. In order to facilitate this, the development of a greater understanding of ritual would be helpful and necessary. ${ }^{2}$

In addition, a number of us in the project think that Confucianism might provide an interesting, perhaps useful, alternative to the Western approach. Confucians were first and foremost ritual specialists; they led a form of life that was steeped in ritual, a fact which they were also clearly cognisant of. Hence, their philosophical expressions are largely a result of a reflection from, and about, their way of life. Moreover, as mentioned in Ranie Villaver's paper, the term, $l i$, for ritual in Confucianism has an expansive scope, which ranges from the great rite of the emperor's sacrifice to the heavens to that of the ordinary rituals of daily interaction. The ordinary, because of ritual, is also imbued with a vital significance, one that is not dependent upon a transcendent reality that is totally other. ${ }^{3}$ Such a framework offers an alternative to the standard Christianised account of religious traditions that is built upon a metaphysics that privileges the transcendent. ${ }^{4}$

Regarding Villaver's suggestion that the Confucian notion of $l i$, understood in his paper as behavioural propriety, is a universal notion, might need some clarification. In some ways the suggestion is perfectly obvious; that is to say, the term as it is expressed is an abstracted philosophical notion, and therefore is universal in scope. It is therefore not a claim about the metaphysical status of $l i$. Nevertheless, apart from its being expressed as a philosophical notion, in practice $l i$ also involves a code of behaviour based on consanguineous relationships, a code that is culturally specific to the Chinese. Therefore, when Vietnam, Korea and Japan adopted Confucian $l i$, it involved adopting and adapting Chinese ritual order according to their own circumstances. Such a manner of adopting Confucian teachings and practices is not what we have in mind, and would not be congenial to our interest in 
maintaining cultural uniqueness which involves the local community having custodianship of their own rituals. Such a view may have consequences for approaches that seek to maintain orthopraxy.

In so far as there are elements in Confucianism that are universal or general in scope, it might lie in Villaver's discussion on whether propriety (as an abstraction of $l i$ ) or humane feelings have priority in the process of becoming a fully fledged human being. Learning how to behave appropriately within the community is the means by which one can come to have humane feelings for one another. This might be an insight that has general appeal, as it can be used by different cultures - despite having different codes of proper behaviour, they commonly value humane feelings. Nevertheless, the foregoing remains an articulation of Confucian philosophy, a world religious tradition. This raises the question, to what extent does such generalised ideas drawn from Confucianism constitute an alternative to the Western framework? Regarding this, many lessons could be learned from those cultures that have been influenced by Confucianism: what aspects of their indigenous tradition have been preserved, how are they achieved, and at what cost?

Finally, a note of caution and reservation. It concerns the value we place on cultural diversity. To the extent that diversity is a value, might not this project in fact lead to its opposite; by our interacting with, and learning from each other, might the result be in fact a greater homogenisation of cultures? Would a better way to maintain diversity be to allow each culture to pursue their own path without having to take heed of what others are doing? But surely, given the current trend of an increasingly interconnected world, an isolationist approach is becoming more difficult to maintain. Moreover, apart from extreme cases, traditionally, communities have never existed in isolation - exchanging of cultural goods and transferring of knowledge with other communities have been common occurrences over the ages. On the other hand, while diversity is a value, it cannot be absolute; one needs its other side - sameness. For even within a small community, there needs be both agreement and difference among its members in order for it to be viable. Diversity taken to the extreme results in a community with a membership of one. We recognise that the boundaries of cultures are changeable and fluid; and we do not hold the view that the current status quo must always be maintained. But at the same time, there are circumstances when such changes have occurred in ways that were violent and unjust. Our position and sympathy are with those less advantaged and oppressed. We are of the opinion that the wish of any culture that seeks to assert its identity and express its philosophy ought to be respected. 


\section{NOTES}

1 "Catherine Bell... sees one of the fundamental characteristics of ritualization as "the simple imperative to do something in such a way that the doing itself gives the acts a special or privileged status"” (Bell 1997: 166, cited in Seligman et al., 2008: 4).

2 "...ritual [is seen as] a particular form of orientation to action, a frame that tells us how to understand actions like lightning a candle or sitting quietly in a chair" (Seligman et al. 2008: 4).

3 See works such as Seligman et al. (2008) in which social actions are analysed under the categories of Ritual and Sincerity, which are understood as ideal types.

4 For a seminal account of the significance of the ordinary in Confucian thought, see Fingarette (1972).

5 We need to be careful not to overstate the point about transcendence in Christian thought. Max Charlesworth, when discussing the Australian aboriginal understanding of "the Dreaming" in the context of Judaeo-Christian view of creation, states, "For the medieval Jewish-Christian-Islamic philosopher-theologians the fact that God is transcendent to the created world does not mean that God cannot be immanent in that world. ...one could say that...the Jewish-Christian-Islamic tradition has perhaps exaggerated the transcendence of God..." From Charlesworth (2005: 20).

\section{REFERENCES}

Bell, C. 1997. Ritual: Perspectives and dimensions. New York: Oxford University Press. Charlesworth, M. 2005. Introduction. In Aboriginal religions in Australia: An anthology of recent writings, eds. Charlesworth, M., Dussart, F. and Morphy, H. Aldershot, 1-27. London: Ashgate.

Fingarette, H. 1972. Confucius: The secular as sacred. New York, Hagerstown, San Francisco, London: Harper and Row.

Seligman, A. et al. 2008. Ritual and its consequences: An essay on the limits of sincerity. New York: Oxford University Press. 